\title{
Variations in the correlation between teleconnections and Taiwan's streamflow
}

\author{
Chia-Jeng Chen ${ }^{1}$ and Tsung-Yu Lee ${ }^{2}$ \\ ${ }^{1}$ National Chung Hsing University, 145 Xingda Road, South District, Taichung 40227, Taiwan \\ ${ }^{2}$ National Taiwan Normal University, 162 Heping East Road, Section 1, Taipei 10610, Taiwan \\ Correspondence to: Tsung-Yu Lee (tylee@ntnu.edu.tw)
}

Received: 6 February 2017 - Discussion started: 28 February 2017

Revised: 1 June 2017 - Accepted: 9 June 2017 - Published: 12 July 2017

\begin{abstract}
Interannual variations in catchment streamflow represent an integrated response to anomalies in regional moisture transport and atmospheric circulations and are ultimately linked to large-scale climate oscillations. This study conducts correlation analysis to calculate how summertime (July-September, JAS) streamflow data derived at 28 upstream and 13 downstream gauges in Taiwan correlate with 14 teleconnection indices in the current or preceding seasons. We find that the western Pacific (WP) and PacificJapan (PJ) patterns, both of which play a critical role in determining cyclonic activity in the western North Pacific basin, exhibit the highest concurrent correlations (most significant $r=0.50$ ) with the JAS flows in Taiwan. Alternatively, the Quasi-Biennial Oscillation (QBO) averaged over the period from the previous October to June of the current year is significantly correlated with the JAS flows (most significant $r=-0.66$ ), indicating some forecasting utility. By further examining the correlation results using a 20-year moving window, peculiar temporal variations and possible climate regime shifts (CRSs) can be revealed. A CRS test is employed to identify suspicious and abrupt changes in the correlation. The late 1970s and 1990s are identified as two significant change points. During the intermediate period, Taiwan's streamflow and the PJ index exhibit a marked inphase relationship $(r>0.8)$. It is verified that the two shifts are in concordance with the alteration of large-scale circulations in the Pacific basin by investigating the changes in pattern correlation and composite maps before and after the change point. Our results suggest that empirical forecasting techniques should take into account the effect of CRSs on predictor screening.
\end{abstract}

\section{Introduction}

Hydro-climatic forecasting is a crucial issue, particularly for those regions suffering increased rainfall intensity and/or reoccurring, persistent droughts in a changing climate. An established method for hydro-climatic forecasting is the usage of "teleconnection" patterns (van den Dool, 2007) that signify the influence of low-frequency climate oscillations on hydro-climates in remote locations by emanating shifts in meteorological systems (e.g. planetary waves, jet streams, and monsoons). Prominent teleconnection patterns have proven useful for regional climate prediction with lead times from weeks to months (e.g. Palmer and Anderson, 1994; Chiew et al., 1998; Goddard et al., 2001). In Taiwan, the development of such a prediction model is challenging because of mixed weather systems in different seasons, including spring rains, Mei-Yu, and East Asian monsoons from spring to summer, typhoons from summer to autumn, and the Mongolian high-pressure system and associated northeastern monsoons in winter (Yihui and Chan, 2005; Chen and Chen, 2011). Besides, the influence of those weather systems on precipitation can further be modulated by the Central Mountain Range (topographic variations) and varied climate zones (latitudinal differences, Huang et al., 2012). While challenging, the search for the relationship between Taiwan's climate in the wet season and large-scale circulations can guide the development of a hydro-climatic forecasting framework beneficial to water resource management in this area.

In the equatorial Pacific, the El Niño-Southern Oscillation (ENSO) stands out as the leading mode and has dramatic impacts on global and regional climates (Ropelewski and Halpert, 1986, 1987, 1989, 1996; Kiladis and Diaz, 
1989; Harrison and Larkin, 1998; Dai and Wigley, 2000; McCabe and Dettinger, 1999; Wang et al., 2000). In recent years, discussion regarding non-canonical ENSO (e.g. central Pacific El Niño or El Niño Modoki, Ashok et al., 2007) and associated impacts has stimulated a significant increase in ENSO-related research. To better quantify and monitor the ENSO, researchers have defined several ENSO indices, including NINO 1 + 2, NINO 3, NINO 4, and NINO 3.4 (e.g. Trenberth, 1997; Trenberth and Stepaniak, 2001). In addition to ENSO, teleconnection patterns over fields of atmospheric variables (e.g. sea level pressure and $500 \mathrm{mb}$ geopotential height) have been recognized using various statistical techniques, such as correlation analysis (Wallace and Gutzler, 1981) and rotated principal component analysis (Barnston and Livezey, 1987). Prominent teleconnection patterns include the North Atlantic Oscillation (NAO, Hurrell, 1995), Pacific North American (PNA, Wallace and Gutzler, 1981; Barnston and Livezey, 1987), Indian Ocean Dipole (IOD, Saji et al., 1999), West Pacific (WP, Barnston and Livezey, 1987), East Pacific-North Pacific (EP-NP, Barnston and Livezey, 1987), Pacific-Japan (PJ, Nita, 1987; Kosaka and Nakamura, 2006), Arctic Oscillation (AO, Thompson and Wallace, 1998), and Antarctic Oscillation (AAO, Gong and Wang, 1999), Pacific Decadal Oscillation (PDO, Mantua et al., 1997), and Atlantic Multidecadal Oscillation (AMO, Schlesinger and Ramankutty, 1994; Enfield et al., 2001). All of the above interannual and interdecadal oscillations have been shown to have widespread impacts on regional and global climate systems.

The usage of teleconnection patterns for streamflow forecasting has been published by a number of previous studies. Earlier work can be exemplified by Kahya and Dracup (1993) and Hamlet and Lettenmaier (1999); whereas the former examined the relationship between ENSO and the unimpaired streamflow over the contiguous United States, the latter devised an empirical model for forecasting of the Columbia River streamflow using ENSO and PDO. Another earlier work by Chiew et al. (1998) linked ENSO to the Australian streamflow, and then Chiew and McMahon (2002) later extended their discussion to global ENSO-streamflow teleconnection. More recently, Moradkhani and Meier (2010) adopted various teleconnection indices along with several climate variables and then employed a principal component regression model for streamflow forecasting in two Pacific Northwest basins; Robertson and Wang (2012) applied a Bayesian approach to select predictors from a pool of 13 teleconnection indices for seasonal streamflow forecasting in Australia; Hidalgo-Muñoz et al. (2015) used multiple linear regression with 20 teleconnection indices as potential predictors to forecast seasonal streamflow over the Iberian Peninsula.

From the above studies, it is noted that, while the usage of a comprehensive list of teleconnection indices appears to be the trend, most studies payed less attention to the diagnostics of underlying predictability and the caveats of intrinsic co- variability between regional streamflow and large-scale circulations. Besides, using teleconnection patterns for hydroclimatic forecasting comes with a caveat: the existence of climate regime shifts (CRS). The occurrence of a CRS indicates deterioration or even a possible break-off of the relationship between regional hydro-climates and certain circulation patterns. Many researchers have identified notable CRSs in the Pacific basin (e.g. in the late 1970s by Miller et al., 1994, and Hare and Mantua, 2000, and in the late 1990s by McPhaden et al., 2011, and Hong et al., 2014a).

To the best of our knowledge, similar work applied to Taiwan has not yet been conducted, although several studies (e.g. Wang et al., 2000; Yang et al., 2002; Wang and Fan, 2005; Choi et al., 2012) have investigated the various effects of teleconnection patterns on East Asian regions. The main motivation for our work thus comprises two primary objectives:

1. to investigate the correlations between Taiwan's seasonal streamflow and teleconnection patterns; and

2. to verify the existence of any CRS signals in the correlation and discuss associated changes in large-scale circulation patterns.

The rest of this paper is organized as follows. Section 2 describes the data and analysis procedures used in this study. Section 3 presents the results of correlation and CRS analyses. Section 4 further discusses the implication of CRSs for seasonal forecasting. Section 5 provides a summary of our findings and concluding remarks.

\section{Data and analysis procedures}

Taiwan's geographical location, major watersheds and subcatchments are shown in Fig. 1. Streamflow data in the watersheds will be correlated with selected teleconnection indices. In the subsections below, the specifications and sources of the streamflow, teleconnection index, and other auxiliary data will be described, followed by the analysis procedures used in this study.

\subsection{Streamflow data, teleconnection indices, and other data sets}

Streamflow data used in this study are obtained from the Water Resources Agency in Taiwan, the primary authority in charge of installing and monitoring most of the river gauges over the country, and from the Taiwan Power Company, measuring streamflow for the sake of hydroelectricity. We select a total of 28 upstream and 13 downstream gauges of satisfactory quality and extended record. The collective contributing area associated with those downstream gauges located at the outlets of 13 major watersheds is approximately $16731 \mathrm{~km}^{2}$, $\sim 46 \%$ of Taiwan's territory. Because streamflow data observed at the downstream gauges are subject to human in- 
Table 1. Periods of data record and missing data percentages for all 41 catchments used for our analysis. Note that we use only JAS data in each year, and the missing data percentage is referred to as the percentage of years in which no JAS data are available.

\begin{tabular}{llr|llr|llr}
\hline $\begin{array}{l}\text { Catchment } \\
\text { (downstream) }\end{array}$ & $\begin{array}{l}\text { Period of } \\
\text { record }\end{array}$ & $\begin{array}{r}\text { Missing } \\
\text { data \% }\end{array}$ & $\begin{array}{l}\text { Catchment } \\
\text { (upstream) }\end{array}$ & $\begin{array}{l}\text { Period of } \\
\text { record }\end{array}$ & $\begin{array}{r}\text { Missing } \\
\text { data } \%\end{array}$ & $\begin{array}{l}\text { Catchment } \\
\text { (upstream) }\end{array}$ & $\begin{array}{l}\text { Period of } \\
\text { record }\end{array}$ & $\begin{array}{r}\text { Missing } \\
\text { data \% }\end{array}$ \\
\hline TC & $1951-2013$ & $0 \%$ & Cat01 & $1970-2013$ & $2.3 \%$ & Cat15 & $1970-2013$ & $2.3 \%$ \\
HLO & $1981-2013$ & $0 \%$ & Cat02 & $1970-2006$ & $0 \%$ & Cat16 & $1971-2013$ & $0 \%$ \\
WU & $1966-2013$ & $2.1 \%$ & Cat03 & $1970-2002$ & $0 \%$ & Cat17 & $1970-2013$ & $11.4 \%$ \\
JS & $1965-2009$ & $0 \%$ & Cat04 & $1970-2002$ & $0 \%$ & Cat18 & $1971-2013$ & $2.3 \%$ \\
BG & $1949-2013$ & $0 \%$ & Cat05 & $1971-2007$ & $0 \%$ & Cat19 & $1970-2013$ & $11.4 \%$ \\
ZW & $1960-2013$ & $0 \%$ & Cat06 & $1972-2013$ & $2.4 \%$ & Cat20 & $1970-2013$ & $11.4 \%$ \\
ER & $1971-2013$ & $0 \%$ & Cat07 & $1970-2008$ & $0 \%$ & Cat21 & $1970-2013$ & $11.4 \%$ \\
GP & $1951-2010$ & $0 \%$ & Cat08 & $1976-2013$ & $5.3 \%$ & Cat22 & $1970-2001$ & $0 \%$ \\
BN & $1948-2013$ & $4.5 \%$ & Cat09 & $1972-2013$ & $0 \%$ & Cat23 & $1974-2013$ & $5 \%$ \\
SGL & $1969-2013$ & $0 \%$ & Cat10 & $1970-2013$ & $0 \%$ & Cat24 & $1977-2011$ & $5.7 \%$ \\
HLI & $1969-2013$ & $0 \%$ & Cat11 & $1970-2013$ & $2.3 \%$ & Cat25 & $1977-2011$ & $2.9 \%$ \\
HP & $1975-2013$ & $5.1 \%$ & Cat12 & $1970-2008$ & $0 \%$ & Cat26 & $1970-2012$ & $2.3 \%$ \\
LY & $1949-2009$ & $0 \%$ & Cat13 & $1970-2013$ & $9.1 \%$ & Cat27 & $1970-2013$ & $0 \%$ \\
& & & Cat14 & $1970-2013$ & $4.5 \%$ & Cat28 & $1970-2013$ & $2.3 \%$ \\
\hline
\end{tabular}

tervention (e.g. water regulation and withdrawal for various consumption), a distinction has been made to separate those upstream gauges with pristine flows from the downstream gauges, as shown in Fig. 1. From here onward, two batches of the same analysis will be performed for the upstream and downstream data. To minimize the effect of human intervention on streamflow data, this study emphasizes data during the high-flow season instead of low-flow seasons when more frequent regulations occur. Without loss of generality, July to September (JAS) is identified as the target high-flow season, from which seasonal streamflow data are aggregated for our follow-up analysis. It is noted that JAS is also known as the major typhoon season in Taiwan.

The periods of record and the missing data percentages for all 41 catchments are listed in Table 1. One sufficient condition for correlation analysis is a long period of data record. Thus, we decide to use all available data even though some of their periods of record differ: 30 out of 41 gauges present less than $3 \%$ missing data (e.g. 1 out of 40 years is missing), indicating the reasonable quality of JAS flow data. For those missing-data years, we simply skip the flow and teleconnection index data pair for the calculation of correlation values to avoid the creation of any artificial, subjective flow quantities from data filling.

JAS streamflow data prepared thus far for the upstream and downstream gauges represent our target variable to be correlated with the major teleconnection indices. This correlation analysis is purposeful since the major teleconnection patterns can emulate a miniature of the full-scale climate system for considerable climate variability explained, thereby providing some clues regarding the causations of the interannual variations of Taiwan's streamflow. A list of the major teleconnection indices has been compiled. The desired list should cover as many teleconnection patterns as possible,

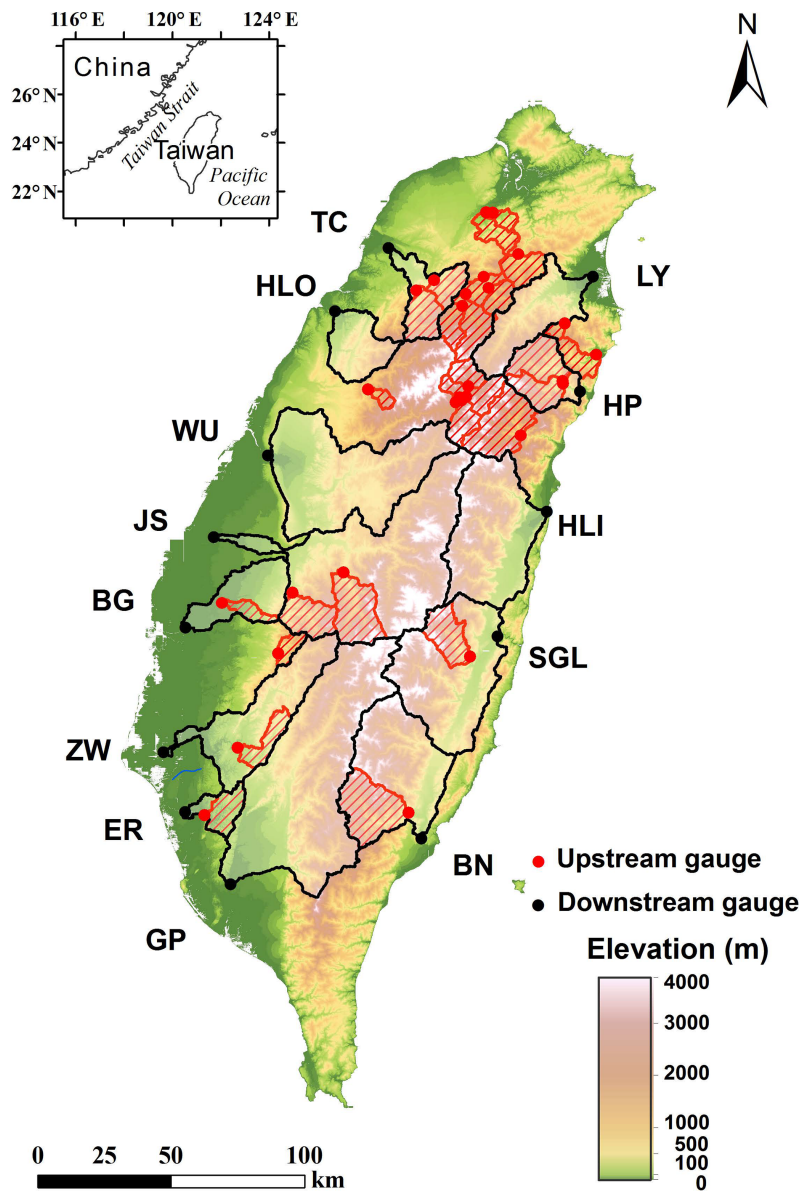

Figure 1. Thirteen major watersheds (black boundaries with abbreviations near the outlets) of Taiwan and 28 upstream catchments (red shadings) analysed in this study. 
Table 2. List of the 14 teleconnection indices used in this study.

\begin{tabular}{llll}
\hline Teleconnection index & Full form (variable*) & Source & Sample reference \\
\hline AMO & Atlantic Multidecadal Oscillation (SST) & NOAA/ESRL/PSD & Enfield et al. (2001) \\
PDO & Pacific Decadal Oscillation (SST) & http://jisao.washington.edu & Mantua et al. (1997) \\
NINO 1+2 & ENSO index at the eastern equatorial Pacific (SST) & NOAA/NCEP/CPC & Trenberth (1997) \\
NINO 3.4 & ENSO index at the eastern-central Pacific (SST) & NOAA/NCEP/CPC & Trenberth (1997) \\
NINO 4 & ENSO index at the central Pacific (SST) & NOAA/NCEP/CPC & Trenberth and Stepaniak (2001) \\
IOD & Indian Ocean Dipole (SST) & http://www.jamstec.go.jp & Saji et al. (1999) \\
EPNP & East Pacific-North Pacific (500 mb HGT) & NOAA/ESRL/PSD & Barnston and Livezey (1987) \\
PNA & Pacific North America (500 mb HGT) & NOAA/ESRL/PSD & Wallace and Gutzler (1981) \\
AO & Arctic Oscillation (1000 mb HGT) & NOAA/NCEP/CPC & Thompson and Wallace (1998) \\
AAO & Antarctic Oscillation (700 mb HGT) & NOAA/ESRL/PSD & Gong and Wang (1999) \\
NAO & North Atlantic Oscillation (500 mb HGT) & NOAA/ESRL/PSD & Hurrell (1995) \\
QBO & Quasi-Biennial Oscillation (30 mb UWND) & NOAA/ESRL/PSD & Naujokat (1986) \\
WP & Western Pacific (500 mb HGT) & NOAA/ESRL/PSD & Barnston and Livezey (1987) \\
PJ & Pacific-Japan (SLP) & From Hisayuki Kubota & Kubota et al. (2016) \\
\hline
\end{tabular}

* SST, HGT, UWND, and SLP stand for sea surface temperature, geopotential height, zonal wind, and sea level pressure, respectively.

but those selected should show certain signs of connections to East Asian climate based on previous entries in the literature. The ENSO is characterized as an air-sea coupled phenomenon: a zonal sea level pressure (SLP) anomaly in the tropical Pacific (i.e. the Southern Oscillation) and a quasiperiodic sea surface temperature (SST) warming/cooling in the tropical eastern Pacific (i.e. El Niño/La Niña). As the impact of ENSO on East Asian climate is well known, the list begins with three ENSO indices, namely NINO $1+2$, NINO 3.4, and NINO 4, which represent the sources of influence from the east, eastern-central, and central tropical Pacific, respectively. In the immediate vicinity of the Pacific, the Indian Ocean has the IOD as the leading mode with evidence of steering East Asian monsoons and other weather systems (Guan and Yamagata, 2003), so the IOD index is selected. Over the farther side and higher latitude of the Pacific, the EP-NP and PNA patterns, found to be associated with the intensity and location of the Pacific jet stream (e.g. Yang et al., 2002), are included in the list. Although sprung from the polar regions, more and more studies have indicated that the $\mathrm{AO}$ and $\mathrm{AAO}$ can affect climate variability in remote, subtropical regions (e.g. Wang and Fan, 2005; Choi et al., 2012); it would be reasonable to have these two indices in the list. To account for possible transoceanic interactions addressed by some studies (Hong et al., 2014b), the NAO index, referred to as the meridional seesaw of the SLP field with the northern and southern centres near Iceland and the Azores, respectively, is also included. Furthermore, as the predictand of interest is highly related to summertime tropical cyclone (TC) activity, the list contains the QBO (Quasi-Biennial Oscillation, Baldwin et al., 2001), WP, and PJ indices (Choi et al., 2010; Kosaka et al., 2013). The QBO depicts a quasiperiodic oscillation between easterlies (positive) and westerlies (negative phase) over the lower tropical stratosphere, and the period is approximately $20-36$ months. The WP pattern is one of the leading modes of low-frequency variabil- ity over the North Pacific, consisting of three anomaly centres: a meridional dipole with one centre near the Kamchatka Peninsula and another over the subtropical western North Pacific (WNP), and a third centre over the eastern North Pacific. The PJ pattern is a meridional teleconnection characterized by cyclonic and anticyclonic anomalies over the midlatitude WNP. Beyond the above teleconnection indices, the $\mathrm{PDO}$ and AMO indices, as representatives of the interdecadal oscillations, are also included for the examination of any lowfrequency connections. The PDO is characterized by a longlived ENSO-like pattern that shifts phases with a period of at least 15-25 years, and the AMO is signified with long-term SST variations over the North Atlantic Ocean with a period of 50-70 years. Table 2 displays the list of the teleconnection indices and depicts their sources as well as some key references.

To reveal large-scale patterns pertaining to certain teleconnection indices (or even unprecedented signals) that dominate Taiwan's streamflow variability, this study uses various other data sets, including the Extended Reconstructed Sea Surface Temperature (ERSST Version 4, Huang et al., 2015), NCEP/NCAR Reanalysis SLP, geopotential height, and zonal wind (Kalnay et al., 1996), and Global Precipitation Climatology Project (GPCP Version 2, Adler et al., 2003).

\subsection{Correlation analysis}

In this study, correlation analysis is designed as follows. First, Pearson correlation coefficients between the JAS flow data at each gauge and different teleconnection indices in the same season (e.g. the JAS ENSO index) are calculated, representing the "concurrent" correlations. Second, to explore any forecasting utility, lagged correlations are computed as well. Lagged correlations are calculated between the JAS flow data and the teleconnection indices averaged over the pre- 
ceding 3-, 6-, and 9-month seasons, namely, AMJ, JFMAMJ, and ONDJFMAMJ, respectively. This average scheme, commonly adopted by plentiful forecasting studies (e.g. Rajeevan et al., 2007), can eliminate high-frequency or artificial data disturbances. To examine prediction skills for longer lead times, we also calculate lagged correlations between the JAS flow data and the teleconnection indices averaged over two preceding periods, ONDJFM and the previous OND.

The PJ index supplied by the source (Kubota et al., 2016) is derived from the JJA data only, so we have used the following steps to develop the new PJ index (with Hisayuki Kubota's guidance) to pursue consistent analysis with the remaining indices: we (1) first obtained atmospheric pressure data at Yokohama and Hengchun in Japan and Taiwan, respectively; (2) calculated the JAS (and all other tri-monthly periods, e.g. AMJ, JFM, and the previous OND) average of the atmospheric pressure anomaly and then normalized the values by the standard deviation at each station; and (3) derived the JAS (and all other tri-monthly periods) PJ index from the difference of the two normalized pressure anomalies, and then normalized the index again by its 1979-2009 standard deviation. Using the above steps, we have reproduced the JJA PJ index and produced the new JAS PJ index.

It should be noted that the concurrent analysis does not produce immediate forecasting utility. However, we believe that it is still important to examine concurrent correlations between teleconnection indices and streamflow since many climate patterns have been proven to drive regional climates in the current season. The idea of calculating contemporaneous correlations was best demonstrated by Wallace and Gutzler (1981), who described several dominant teleconnection patterns at the Northern Hemisphere extratropics during winter (e.g. NAO). Besides, one of the most important concurrent relationships witnessed by several operating agencies and research organizations (e.g. CPC and IRI) is the impact of ENSO on world regions. Various maps of the concurrent relationships (e.g. composite and historical probability) have been produced and archived. Over the Indian Ocean basin, the different phases of the IOD are also known to have pronounced concurrent impacts on the formation of the trade wind and the short rains over eastern Africa from October to November (Black et al., 2003; Clark et al., 2003; Behera et al., 2005; Chen and Georgakakos, 2015). In contrast, significant lagged correlations can indeed generate some forecasting utility, but to assess the dynamical mechanisms of the lagged relationships found by statistical approaches is never a trivial task. To use concurrent relationships for forecasting, one can adopt a hierarchical or hybrid approach that applies another empirical or dynamical model to forecast the teleconnection indices in the first instance (e.g. Kim and Webster, 2010). However, the development of a forecasting model is beyond the scope of this study.

One of the most fundamental assumptions of correlation analysis is that the result of such analysis indicates no causality. The result can be two-way; that is, there is no physi- cal implication for a predictor-predictand relationship. However, the assumption held by us is that significant correlations should suggest some large-scale dominance over the localscale hydroclimate since the opposite route of dominance (i.e. the impact of an island-scale disturbance on large-scale circulations) is less intuitive.

\subsection{Climate regime shift test}

As stated in the study objective, the following correlation analysis is the examination of the temporal disruption of found significant correlations. The temporal disruption or abrupt changes in a univariate time series can be commonly identified by using classic, nonparametric techniques, such as the Mann-Whitney-Pettitt (MWP, Pettitt, 1979) and Kruskal-Wallis (KW, Kruskal and Wallis, 1952) tests. However, these techniques are not directly applicable to quantities such as temporal correlations derived from a bivariate time series. Another statistically sound approach to this problem, proposed by Rodionov (2015), is used in this study. Rodionov's method in detecting abrupt changes in the correlation coefficient is based on the fundamental property of variance. If there are two variables of interest, $x$ and $y$ (e.g. the streamflow and teleconnection index), the variance of the sum of $x$ and $y$ can be written as

$S_{x+y}^{2}=S_{x}^{2}+S_{y}^{2}+2 r S_{x} S y$,

where $S^{2}, S$, and $r$ denote the sample variance, standard deviation, and correlation coefficient, respectively. Further, if the two variables have zero mean and unit variance, the above equation can be reduced to

$S_{x+y}^{2}=2(1+r)$.

Note that, because the sample correlation coefficient ranges from -1 to 1 , the above variance is bounded between 0 and 4 . Equation (2) also indicates that the identification of shifts in $r$ is equivalent to that in $S_{x+y}^{2}$. In his previous work, Rodionov (2005) introduced a method for detecting the abrupt shifts in the variance (of a single variable) based on a "sequential $F$-test." Therefore, the same method for the variance of $x$ or $y$ can be applied to the variance of $x+y$, thereby achieving the identification of shifts in the correlation coefficient. In essence, the above method can also be applied to the variance of $x-y$,

$S_{x-y}^{2}=2(1-r)$,

which should theoretically yield similar change points if the $p$-value (computed from Fisher's $r$-to- $z$ transformation, Fisher, 1921) is less than 0.05. As per Rodionov's suggestion, the test is performed for both the sum and difference series to ensure that the minimum $p$-value is attained.

If the variables have not been normalized, Rodionov (2015) stated that some pre-processing work on the time series is required: using the shift detection in the mean (based 

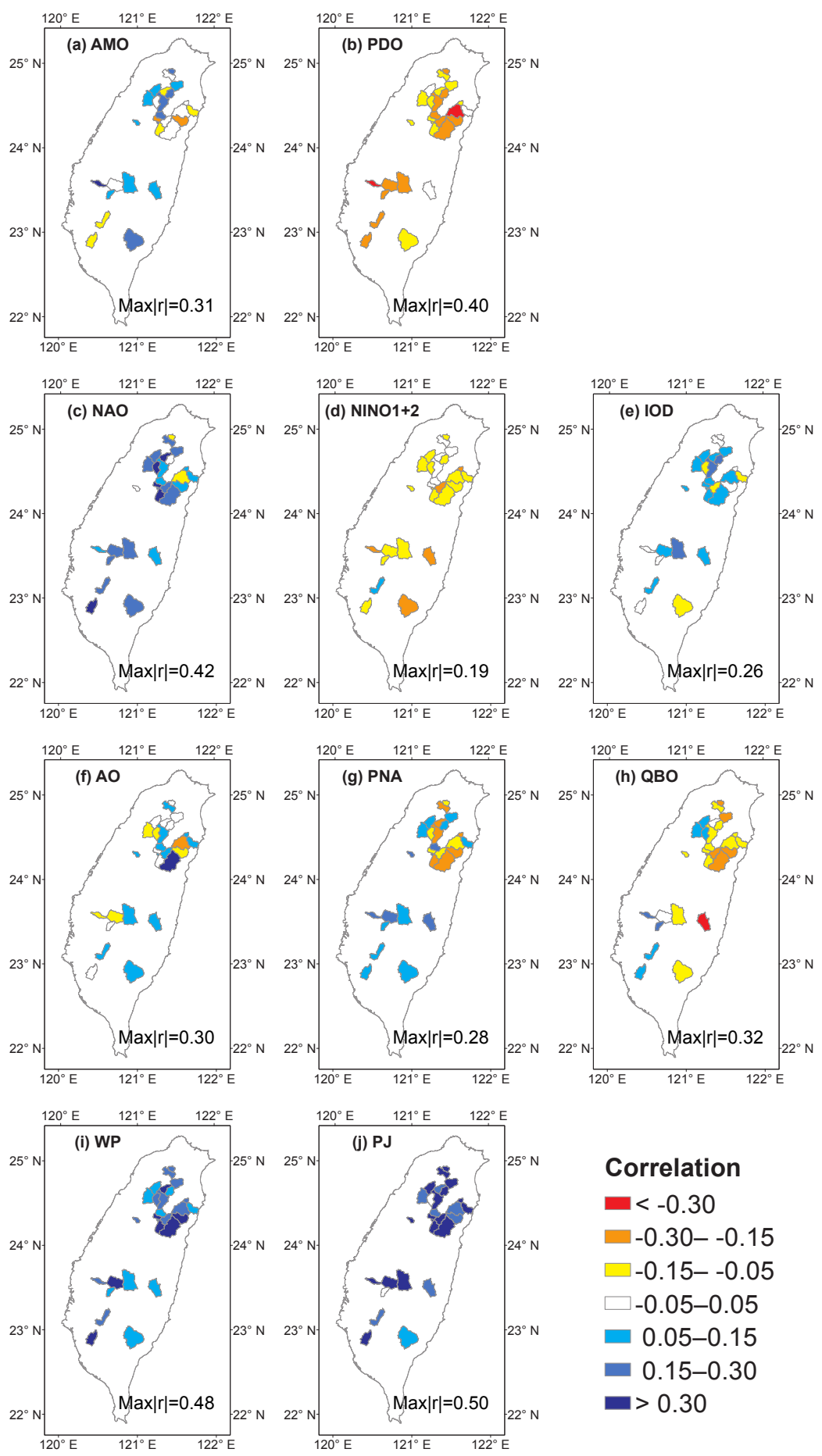

Figure 2. Maps of concurrent correlations showing each upstream catchment. The maximum absolute correlation value among all the catchments is denoted at the bottom of each plot.

on a "sequential $t$-test," Rodionov, 2004) and variance to obtain the stepwise means/trends and variances, respectively. The variables can then be normalized for the shift detection in the correlation coefficient. In addition to the preprocessing work and the desired significance level, a cut- off length $l$ should be determined for the method to detect change points and to calculate associated statistics. For more discussion regarding the caveats of using the CRS detection method and its detailed documentation, please refer to the supplementary material and Rodionov's previous studies. 

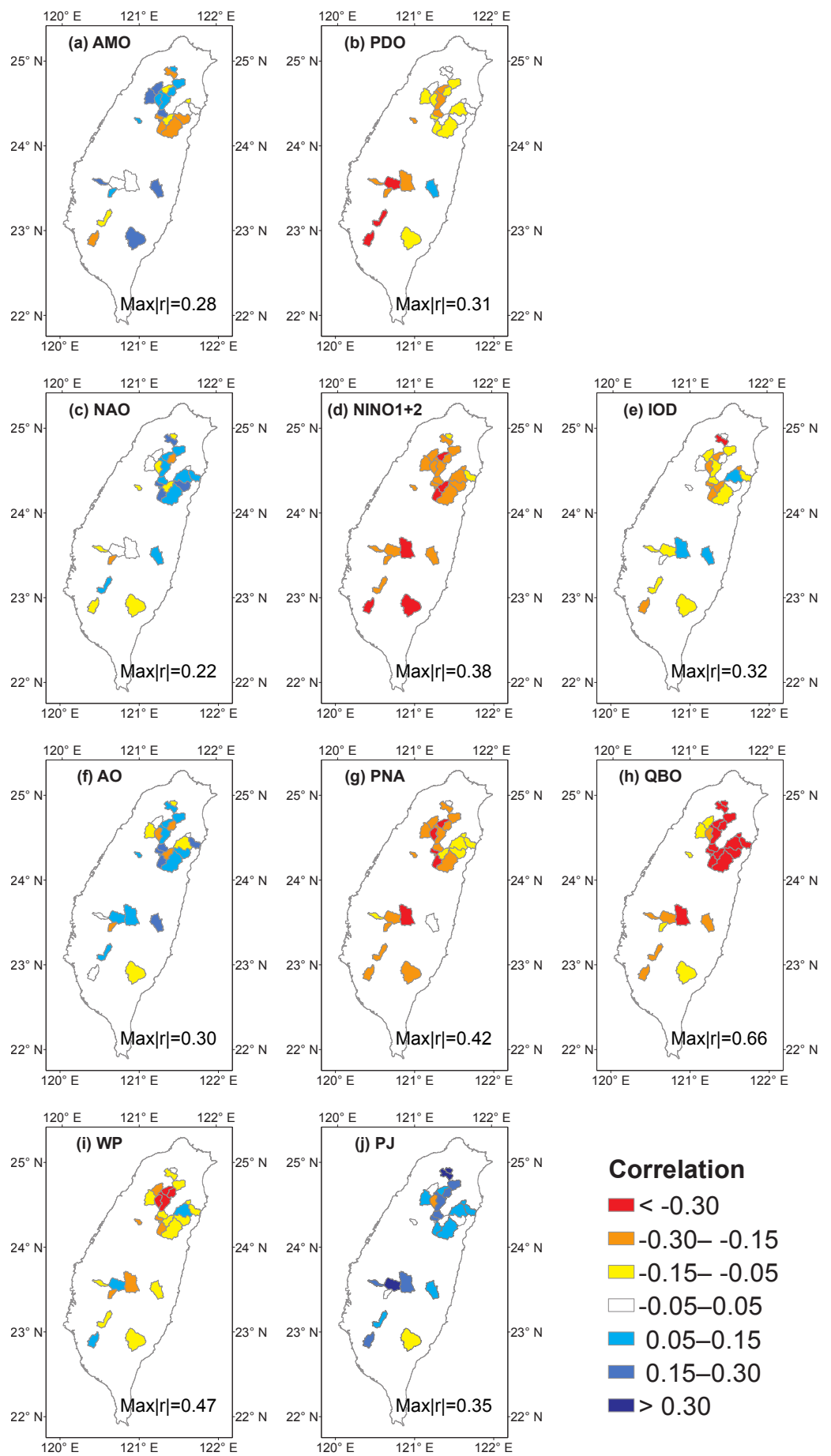

Figure 3. As in Fig. 2 but for lagged correlations (JAS runoff vs. ONDJFMAMA teleconnection indices).

\section{Results}

\subsection{Correlations between Taiwan's runoff and teleconnection indices}

We selectively illustrate the correlation values from the many combinations of the different gauges, teleconnection indices, and lagged periods. In Figs. 2 and 3, concurrent and lagged correlations between the JAS runoff at the upstream gauges and selected teleconnection indices are colour-coded over the maps of the catchments. The criterion for selecting teleconnection indices is that they must exhibit correlation values at the $95 \%$ confidence level with at least one of the catchments under either the concurrent or lagged scenario. In other 
words, those teleconnection indices excluded from the plots do not show significant concurrent or lagged correlations with any of the upstream catchments. Additionally, please note that the lagged correlations shown in Fig. 3 are based on the average period over ONDJFMAMJ only (lagged correlations based on other average periods show quite similar patterns and are available upon request). In the two figures, the highest absolute correlation value among all the upstream catchments for a specific teleconnection index is also denoted in each plot.

Under the concurrent scenario (Fig. 2), (1) many upstream catchments show significant positive correlations with the teleconnection indices, and among these indices, the WP and $\mathrm{PJ}$ indices stand out as having the strongest, universally inphase relationship with the JAS runoff; (2) the only teleconnection index showing all negative correlations with the upstream catchments is the PDO; and (3) surprisingly, the $\mathrm{NAO}$, as the farthest teleconnection mode, shows quite strong correlations ( $\sim 99 \%$ confidence level) with some upstream catchments. Alternatively, under the lagged scenario (Fig. 3), (1) in comparison with the concurrent correlation patterns, some of them experience a clear phase reversal over certain regions of Taiwan (e.g. north-north-east for IOD and WP and central-south-west for PNA); and (2) the most pronounced out-of-phase relationship, even stronger than any of the concurrent correlations, is observed from the QBO index. We will show some evidence of the strong correlations in the discussion section.

To further interpret the range of correlation values, Fig. 4 encapsulates the correlations of the JAS runoff at every gauge against every teleconnection index using box-and-whisker plots. Each box plot constituted by 28 (13) values represents the range of correlations observed from the upstream (downstream) gauges. The results for upstream and downstream gauges are illustrated in the left and right panels, respectively. Concurrent and lagged correlations with JAS, ONDJFMAMJ, ONDJFM, and OND teleconnection indices are shown from the top to bottom of Fig. 4 in sequence. Moreover, the abscissa of Fig. $4 a$ and $b$ is ranked by the mean correlation in each box plot for a clearer illustration of the performance between teleconnection indices. To observe whether a phase transition occurs, the same ranking is then inherited by Fig. $4 \mathrm{c}-\mathrm{h}$. In addition, the corresponding correlation values for all the downstream gauges are also enumerated in Tables 3 and 4 (values for the upstream gauges are available upon request).

Compare Fig. $4 \mathrm{a}$ with $4 \mathrm{~b}$ : the ranking of the teleconnection index is nearly the same (except PNA), and the interquartile range (IQR) of each box plot is also similar, implying the catchment-wide consistency in response to large-scale circulations. The total ranges of correlation values are wider for the upstream, which possibly reflects the higher randomness of catchments at a smaller scale. Under the concurrent scenario, out of the 14 teleconnection indices, 10 (9) tend to positively correlate with the JAS runoff for the upstream (down-

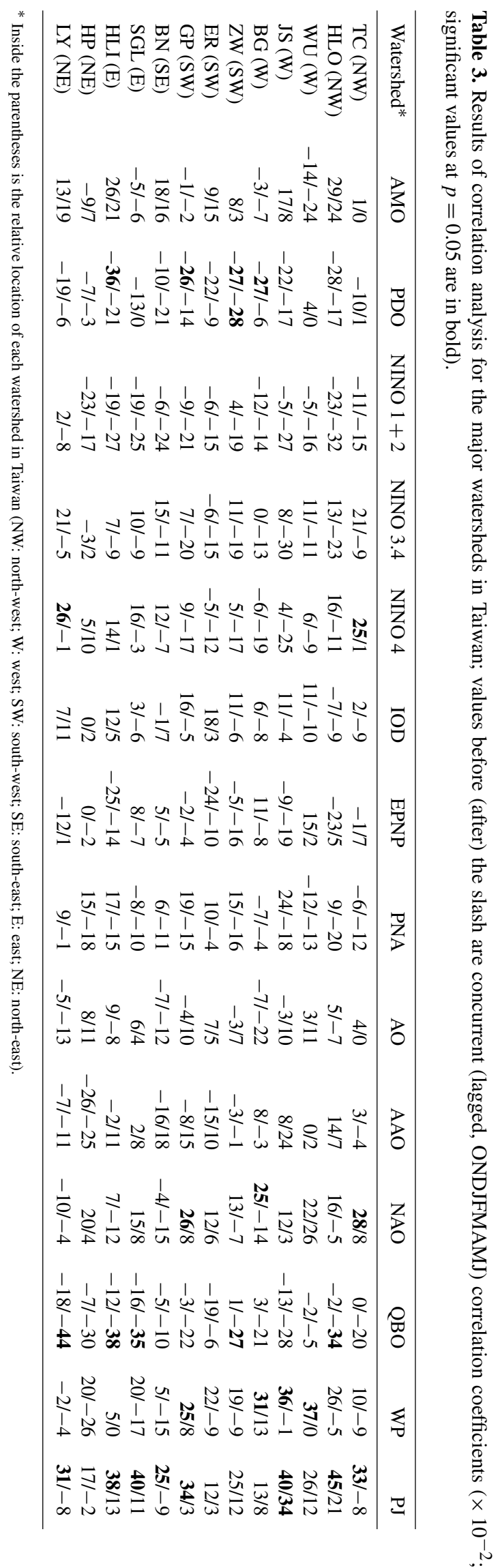

www.hydrol-earth-syst-sci.net/21/3463/2017/ 

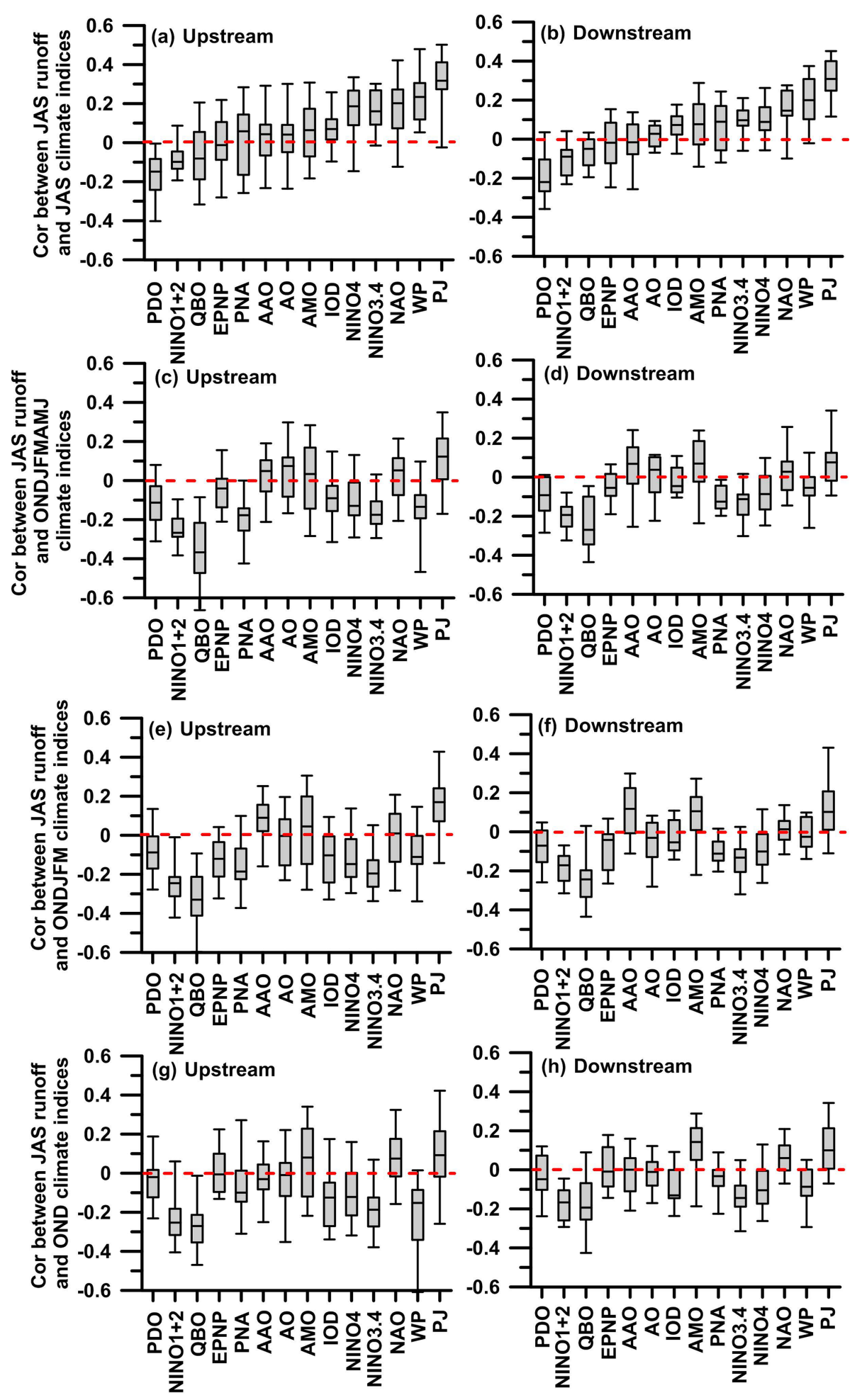

Figure 4. Box plots of correlation values of upstream $(\mathbf{a}, \mathbf{c}, \mathbf{e}, \mathbf{g})$ and downstream $(\mathbf{b}, \mathbf{d}, \mathbf{f}, \mathbf{h})$ runoff with teleconnection indices. From top to bottom are concurrent to lagged correlations derived from teleconnection indices averaged over different seasons. 


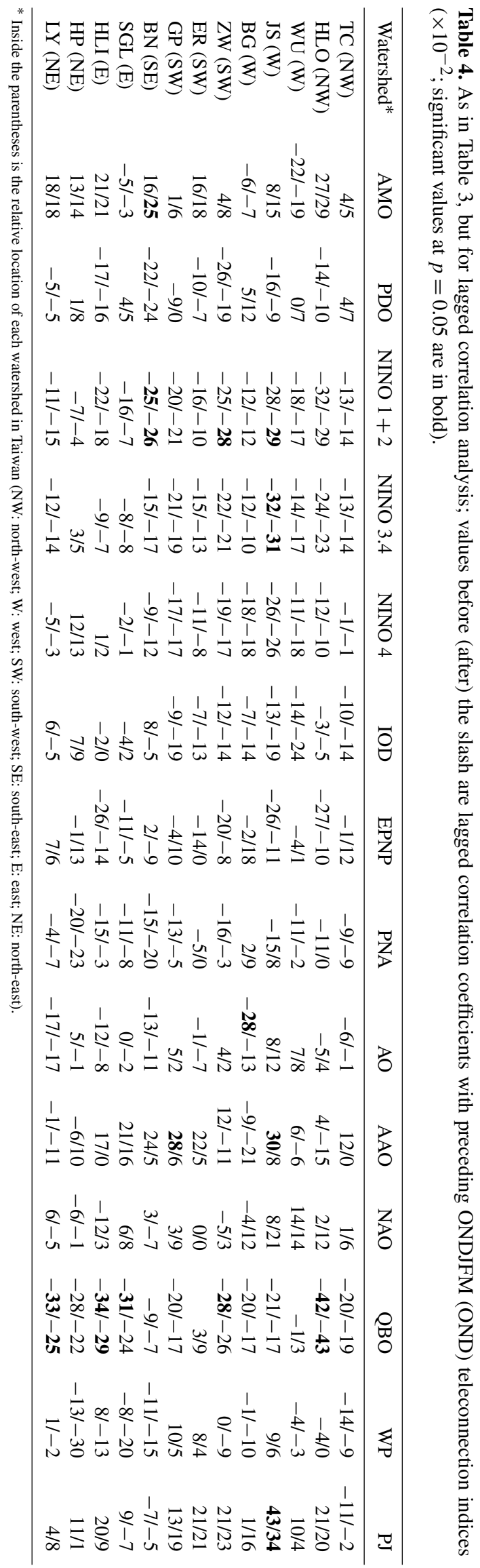

stream). Under the lagged scenario (Fig. 4c and d), only four teleconnection indices remain to positively correlate with the JAS runoff for both the upstream and downstream, suggesting the aforementioned phase reversal. The PNA, IOD, NINO 4, NINO 3.4, and WP are the teleconnection indices showing the phase reversal for both the upstream and downstream. Among all the indices, the QBO again indicates the strongest negative correlations with Taiwan's streamflow as the lead time increases.

\subsection{Regime shifts in the correlation}

Although some of the correlation results for certain catchments against teleconnection indices disclosed above are at a moderate significance level, it is found that these correlations are subject to peculiar interannual variations. For instance, 20-year moving-window correlations with four teleconnection indices, namely the PDO, EPNP, AO, and PJ, are examined (Fig. S1, Supplement). From those plots in Fig. S1, several types of interannual variations as potential signs of CRS can be identified: (1) divergence of the total ranges over time (e.g. panels a, b, and c), (2) a gradual decreasing trend (e.g. panel b), (3) an abrupt increase or decrease (e.g. panels $\mathrm{c}$ and $\mathrm{d}$ ), and (4) a change in sign in the mean correlation near the suspicious CRS year (e.g. panels b and c). We thus hypothesize that the relationship between Taiwan's streamflow and large-scale circulations have undergone several climate regime shifts. To validate this hypothesis and identify possible years of CRS, the CRS test is applied to the streamflow data and teleconnection indices. As a demonstration, the aggregated JAS runoff for eastern (western) Taiwan is computed from the average of HLI and SGL (WU, JS, and BG) data for the CRS test. Figure 5 presents the result of the CRS test for identifying any shifts in the correlation between the eastern and western Taiwan runoff versus the PJ index. The result indicates two highly significant change points in 1979 and 1999 (significant at $p=0.0001$ and 0.0003 , respectively) for the eastern Taiwan runoff. Between 1979 and 1999, the correlation value is higher than 0.8 , suggesting the dominant effect of the PJ pattern. The correlation is remarkable, but it deteriorates drastically after 1999, becoming slightly negative and close to zero. Likewise, two significant change points in 1988 and 2000 (significant at $p=0.006$ and 0.0003 , respectively) can be identified for the western Taiwan runoff. While the first change point is identified in the late 1980s, the marked in-phase relationship between 1979 and 1999 is still notable. The same CRS test has been applied to Taiwan's runoff versus all the other teleconnection indices, but only less significant results can be found.

In the Supplement, we have put the above correlation and CRS analyses in the context of prediction through a hindcasting experiment using linear regression. Overall, using largescale circulation indices can produce fair to good prediction skills in summer streamflow prediction for selected upstream 

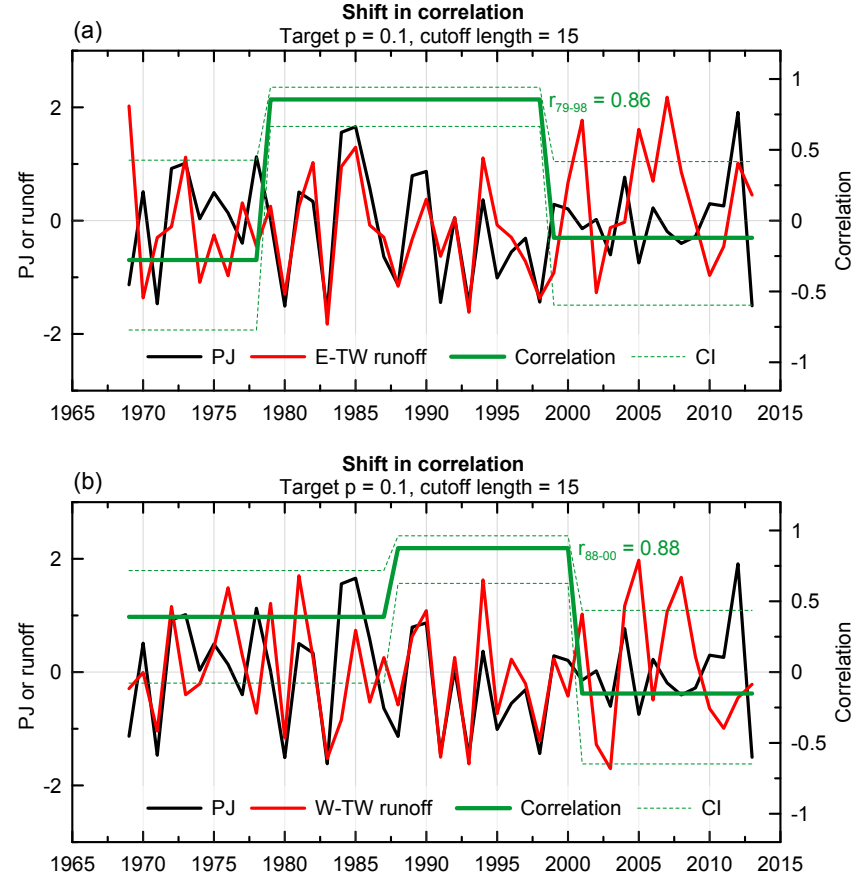

Figure 5. Shifts in the correlation between (a eastern; b western) Taiwan runoff and the PJ index.

and downstream catchments. Regarding the frequent predictors selected as the PDO and PJ indices, the result is consistent with our general correlation assessments (e.g. Table 3) and indicates the general dominance of summer teleconnection in Taiwan. Nevertheless, the regression models illustrate the dramatic variations in prediction skill from the pre- to post-regime shift epoch (Fig. S2). For instance, the crossvalidated correlation value decreases from 0.84 to -0.16 for the SGL watershed (Fig. S2i). To summarize, the linear regression experiment indicates that the assumption of a stable predictor-predictand relationship could be problematic for hydro-climatic forecasting due to the observation of CRS. Please refer to the Supplement for more details about the experiment.

\section{Discussion}

\subsection{Evidence of strong correlations}

Since the WP and PJ indices are associated with cyclonic activity in the WNP, the strong concurrent correlations with the JAS runoff indicate the direct influence of typhoons on Taiwan in summer. It is worth noting that some recent studies (e.g. Mei and Xie, 2016; Liang et al., 2017) have projected more strong typhoons hitting this region, so the JAS runoff is expected to increase. The PDO, on the other hand, also shows the strong (but negative) concurrent correlations; this out-of-phase relationship is supported by some existing find-
Table 5. Change points (shifts in the mean) identified for all the JAS teleconnection indices examined in this study.

\begin{tabular}{ll}
\hline Teleconnection index & Change points \\
\hline AMO & $1962^{* * * *}, 1987^{*}, 1998^{* * *}$ \\
PDO & $1976^{* * * *}, 1998^{* *}, 2010^{* *}$ \\
NINO1+2 & None \\
NINO3.4 & None \\
NINO4 & $1990^{* * * *}$ \\
IOD & $2006^{* *}$ \\
EPNP & $1997^{* * * *}$ \\
PNA & $2002^{* *}$ \\
AO & $1982^{*}$ \\
AAO & None \\
NAO & $1967^{*}, 2006^{*}$ \\
QBO & None \\
WP & $2002^{*}$ \\
PJ & None \\
\hline
\end{tabular}

Significance level is reported by the number of asterisks $\left({ }^{*} p \leq 0.05\right.$; ${ }^{* *} p \leq 0.01 ;{ }^{* * *} p \leq 0.001 ;{ }^{* * * *} p \leq 0.0001$ ).

ings (e.g. Li et al., 2010) regarding the PDO's influence on East Asian climates in general.

To confirm the best outstanding lagged correlation between Taiwan's streamflow and the QBO, additional literature reviews and field significance tests still need to be conducted. The strongest lagged correlation is very likely attributed to the TC activity in the WNP modulated by the QBO. Chan (2003) has performed a cross-spectral analysis between the QBO and the number of TCs in the WNP and indicated that the leading westerly phase of the QBO can result in an increase in TC activity. He explained that the westerly phase of the QBO creates an environment of relatively low vertical wind shear in favour of TC formation. Ho et al. (2009) later found that, during the westerly (easterly) phase of the QBO, more TCs approach the East China Sea (the eastern shore of Japan). Therefore, the negative correlation between the QBO index and TC activity in the vicinity of Taiwan is carried over into the negative correlation with streamflow. In fact, such strong correlations found in 22 out of the 41 catchments also reach field significance. The number of catchments with significant temporal correlations has exceeded the critical value of field significance $(p=0.05)$ from the empirical null distribution (Fig. S3) developed by using a Monte Carlo technique similar to those suggested by Livezey and Chen (1983) and Wilks (2011); 2000 Monte Carlo trials are used, and each trial depicts a significant local test for correlations between the "randomly ordered" QBO index and streamflow data at the 41 catchments, resulting in a count of the number of catchments with significant temporal correlations constituting the null distribution. 


\section{Correlation before and after CRS}
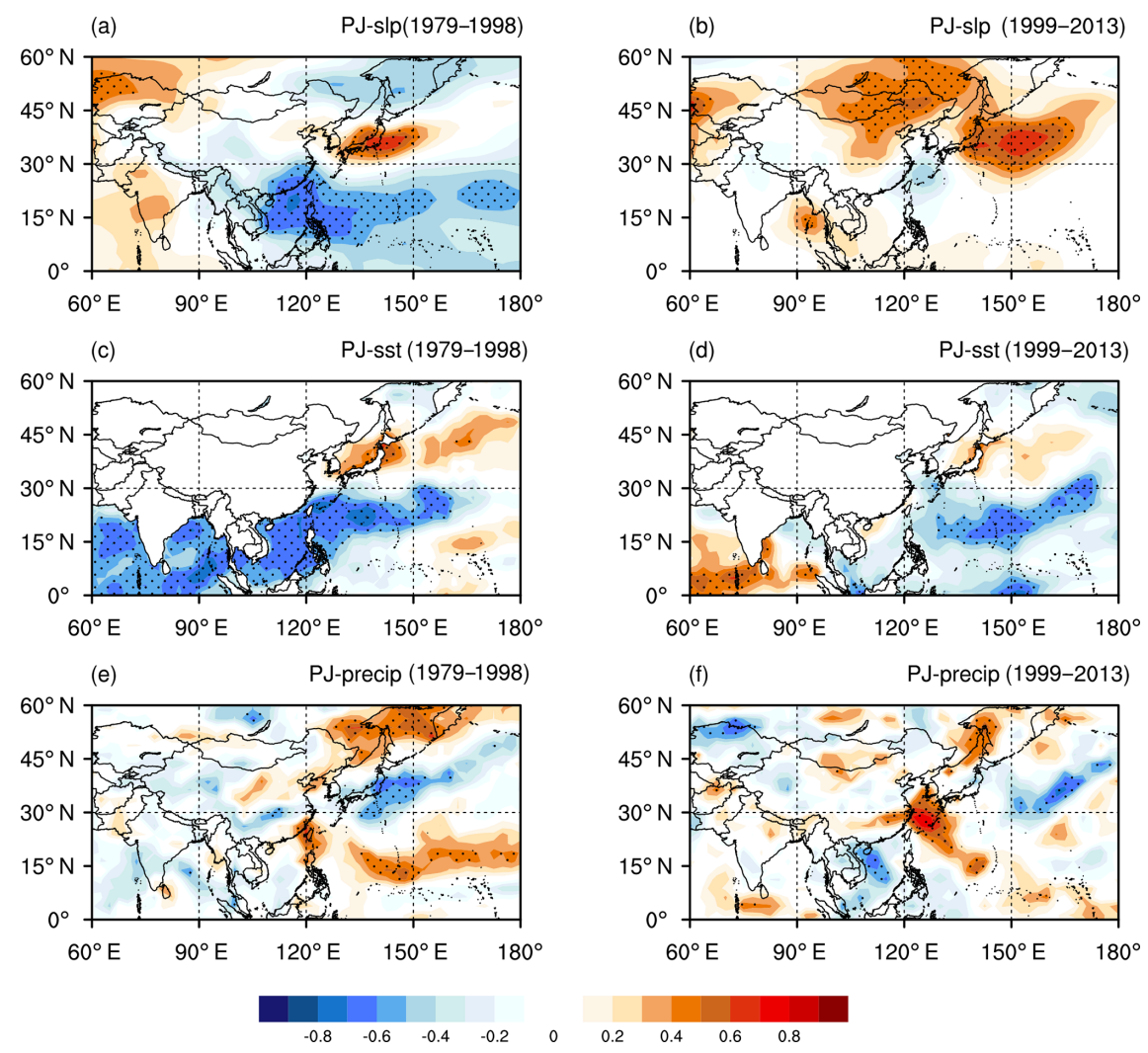

Figure 6. Correlation maps of the PJ index before (a, c, e) and after (b, d, f) the year 1999. The top, centre, and bottom panels are PJ vs. SLP, PJ vs. ERSST, and PJ vs. GPCP data, respectively. Correlation values at a $5 \%$ significance level are stippled.

\subsection{Evidence of CRSs and implication for seasonal forecasting}

In this study, we find that the two change points for the response of Taiwan's streamflow to large-scale circulations are not a coincidence. Whereas the first change point in the late 1970s (for the eastern Taiwan runoff in particular) is likely in relation to the widely known CRS identified over the entire Pacific basin SST (Miller et al., 1994; Hare and Mantua, 2000), the second change point in the late 1990s coincides with the CRS induced by a warming over the equatorial western Pacific (McPhaden et al., 2011; Hong et al., 2014a) and/or more frequent occurrences of the central Pacific El Niño (Xiang et al., 2009). These change points are associated with the shifts in the mean of the teleconnection indices individually. To supplement our explanation here, the CRS analysis of shifts in the mean is also applied to all the teleconnection indices examined in this study, and the identified change points are listed in Table 5. From the table, the shifts in the mean identified for the PDO are consistent with previous studies, and only such shifts (rather than the PJ) are in perfect agreement with the identified shifts in the correlation for Taiwan's streamflow. Therefore, we draw our hy- pothesis regarding the identified CRS as follows: the CRS first emanates from the change in the basin-scale climatology over the Pacific (e.g. shift in the PDO), and then the reorganized large-scale patterns can reset the relationship between the island-scale streamflow with established regional circulations (e.g. the PJ pattern).

The above hypothesis can be supported by some existing findings. Because the PDO is strongly tied to ENSO, the shift in the PDO can induce changes in the ENSO-related SST anomalies as well as ENSO-related teleconnections (Duan et al., 2013). Such SST anomalies have been found to be robust in the WNP during summer (Alexander et al., 2002), and numerical model experiments have verified the ENSOforced PJ pattern (Kosaka et al., 2013). Kubota et al. (2016) further noted that the ENSO-PJ relationship was strengthened after 1980 and then weakened after 2000, likely due to the phase shift in the PDO. When the ENSO-PJ relationship is more pronounced, the systematic impacts of the PJ pattern on TC activity, rainfall, and, subsequently, streamflow in Taiwan are clear. By contrast, if the PJ pattern is less forced by ENSO, the associated impacts can be ambiguous. Consequently, Taiwan's streamflow became less predictable after the post-regime shift epoch. 


\section{Correlation before and after CRS}

(a)
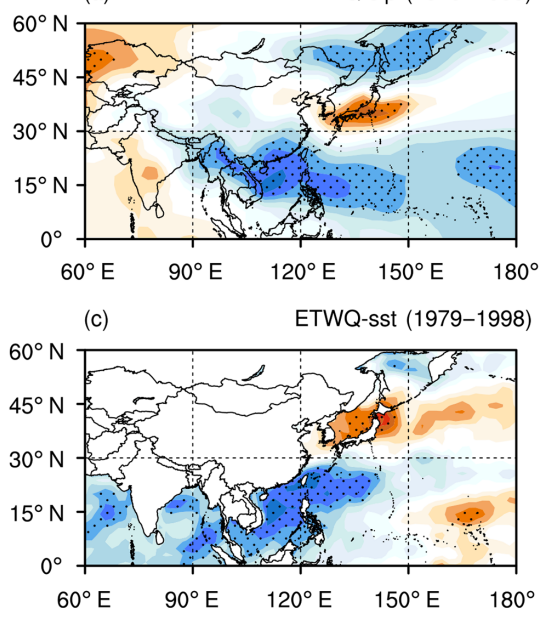

(e)

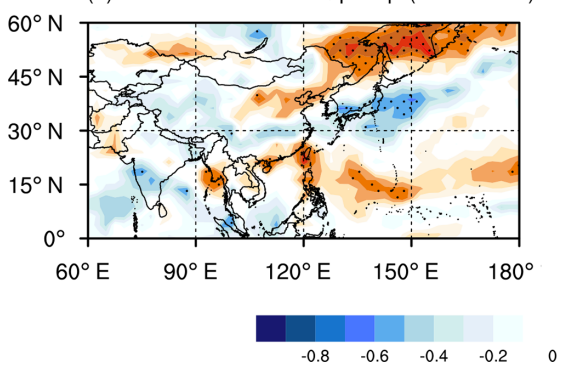

(b)
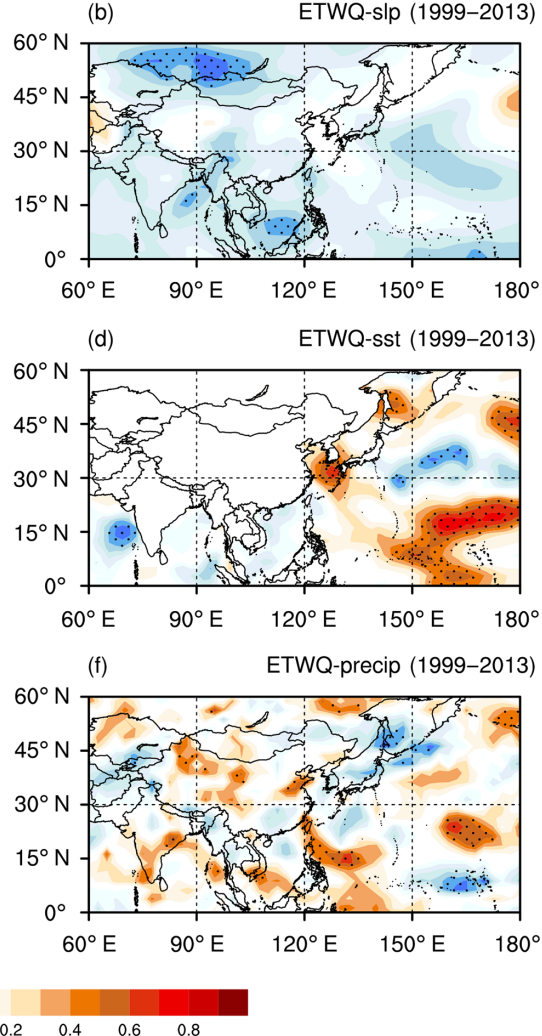

Figure 7. Correlation maps of the eastern Taiwan runoff (ETWQ) before (a, c, e) and after (b, d, f) the year 1999. The top, centre, and bottom panels are ETWQ vs. SLP, ETWQ vs. ERSST, and ETWQ vs. GPCP data, respectively. Correlation values at a $5 \%$ significance level are stippled.

The observation of the CRS can profoundly influence predictor screening for empirical forecasting methods. Conventional predictor screening usually relies on pattern correlation (Chen and Georgakakos, 2014), that is, identifying specific areas over a predictor field (e.g. SST) showing significant correlation with the predictand of interest (e.g. local precipitation or streamflow) over a sufficiently long period of time. This concept holds true if the predictorpredictand relationship remains quasi-stationary. In contrast, if the predictor-predictand relationship is no longer stationary (e.g. identification of a prominent CRS in the correlation), this concept of predictor screening would become questionable. To further illustrate the impact of the CRS on seasonal forecasting, we develop some large-scale diagnostics next.

First, two sets of pattern correlation of the PJ index with the SLP, SST, or GPCP (precipitation) data are generated using 1999 as a demarcation of the time window (Fig. 6). Before 1999, the PJ-SLP correlation indicates a marked dipole pattern with its two poles centred in southern Japan and near Taiwan. Along with the significant negative correlation (at $p=0.05$ ) extended to the Indian Ocean (regarding SST) and the positive correlation over Taiwan (regarding GPCP), all these patterns reasonably reproduce the canonical PJ pattern defined by previous studies (e.g. Kubota et al., 2016). In contrast, from 1999 onward, the entire set of pattern correlation is altered dramatically: the dipole pattern for the PJ-SLP correlation becomes less significant, and the extensive negative correlation over the Indian Ocean for the PJ-SST correlation reverses sign. In addition, the positive correlation originally occupying the Taiwan area migrates north-east to the East China Sea. The above analysis implies that, owing to a possible CRS, a specific teleconnection index (e.g. PJ) can respond quite differently to large-scale circulations from one time window to another. More importantly, if such a teleconnection index is adopted as a predictor, its relationship with the predictand (e.g. precipitation over Taiwan) could largely weaken or even be terminated given the existence of a CRS.

If pattern correlation is calculated directly between the eastern Taiwan runoff (as the predictand) and the SLP, SST, or GPCP data (as the predictor fields), the bulk of significant areas in the predictor fields usually specify the spatial extent of potential predictors. This is in accordance with the common procedure of predictor screening appearing in many articles (DelSole and Shukla, 2009). Figure 7 demonstrates this procedure twice, once before and once after the identi- 

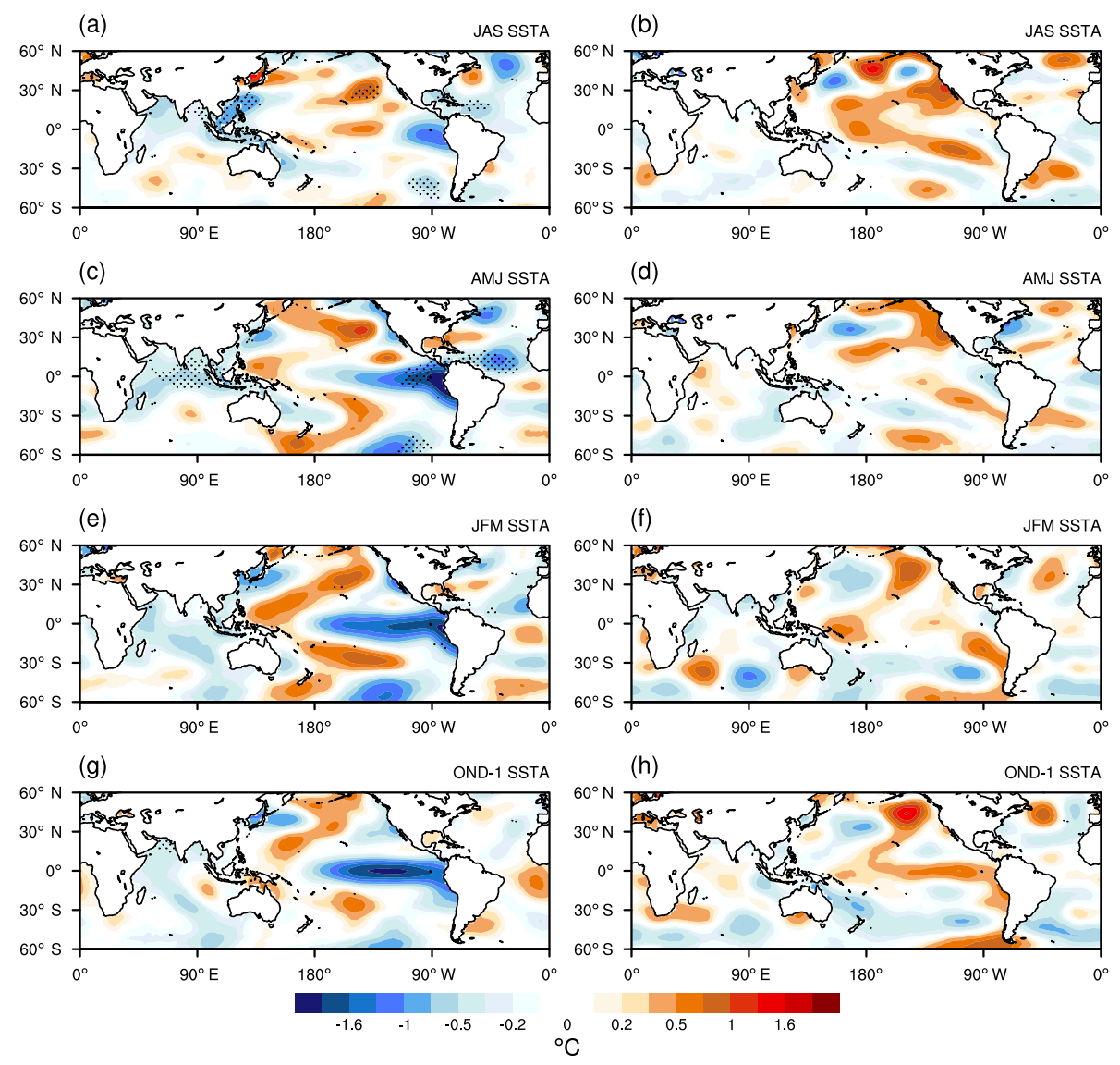

Figure 8. Evolution of SSTA composites from 0- to multi-month lead times based on wet-minus-dry years for the JAS ETWQ before (a, c, e) and after $(\mathbf{b}, \mathbf{d}, \mathbf{f})$ the year 1999. Stippled areas indicate that the SSTA difference is at a $5 \%$ significance level according to a Student's $t$-test.

fied CRS. The left column of Fig. 7 resembles that of Fig. 6 to a very high degree, indicating that the PJ pattern is indeed an ideal predictor candidate before 1999. Nevertheless, from 1999 onward, the right column of Fig. 7 resembles neither the left column of the same figure nor the right column of Fig. 6, implying that the PJ predictor should be replaced by some other predictor candidates.

To achieve some forecasting utility, lead time information can be incorporated into the procedure of predictor screening. For instance, Fig. 8 presents the evolution of the SST anomaly (SSTA) composites based on wet-minus-dry years (i.e. SSTA averaged over the wet years minus that over the dry years) according to the JAS runoff for eastern Taiwan. The composites can reveal significant predictor areas at varied lead times (Chen and Georgakakos, 2015). The identified CRS is used to divide the generation of the SSTA composites. Before the CRS, (1982, 1984, 1985, and 1994) and (1980, 1983, 1993, and 1998) are identified as the wet and dry years, respectively. After the CRS, (2001, 2005, and 2007) and $(1999,2002$, and 2010) are identified as the wet and dry years, respectively. Wet and dry years are identified as those years for which the JAS runoff is higher and lower than the 67th and 33rd percentiles of the entire data series, respectively. During the concurrent season, notwithstanding that Fig. 8a and b show the SSTA patterns as extensions of the patterns observed in Fig. 7c and d, it can be found that the change in the patterns before and after the CRS is significant up to the global scale. With increases in lead times, the two sets of SSTA composites display distinct evolutionary pathways. Eventually, in previous OND, the SSTA composite expresses a La Niña pattern for the before-CRS scenario, completely the opposite of the El Niño pattern for the afterCRS scenario. No significant SST difference relevant to wet or dry can be identified after the CRS, indicating the weakened source of predictability from the SST.

We also examine the evolution of composites for other variables, especially for those used to define such potential predictors as the WP, PJ, and QBO patterns. According to Table 2, these variables represent $500 \mathrm{mb}$ geopotential height, sea level pressure, and $30 \mathrm{mb}$ zonal wind. Therefore, the wet and dry contrasts of these variables, before and after the CRS, are presented in Figs. 9 and 10 using the same for- 
slp composite (wet-dry JAS yr) before and after CRS

(a)

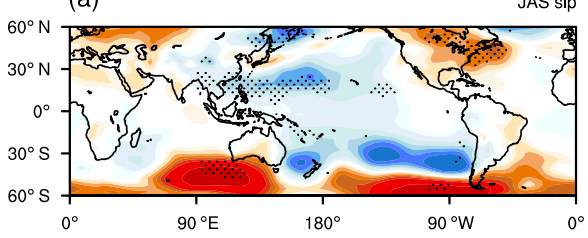

(c)

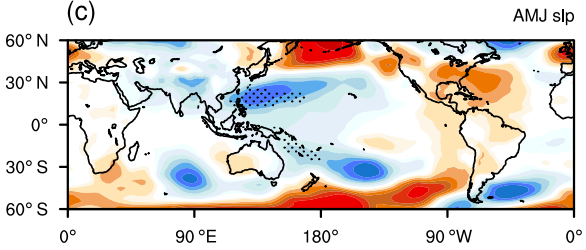

(e)

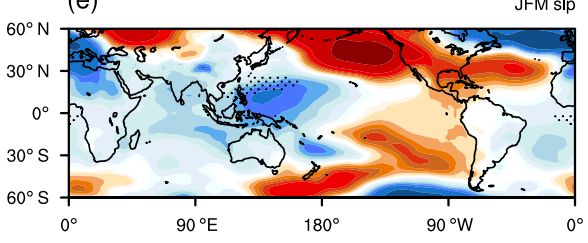

JFM slp

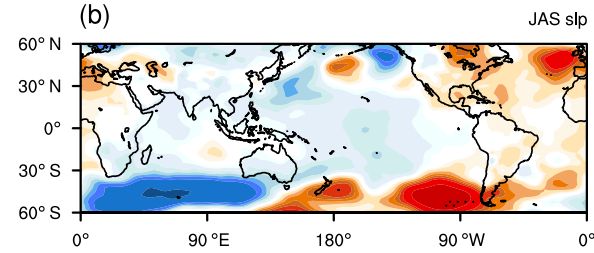

(d)

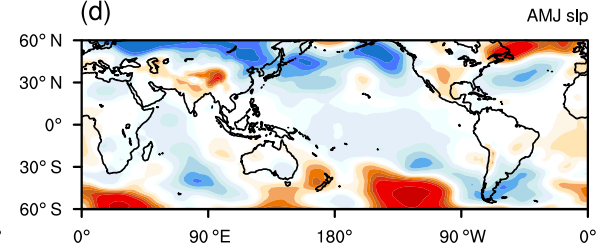

(f) JFM slp

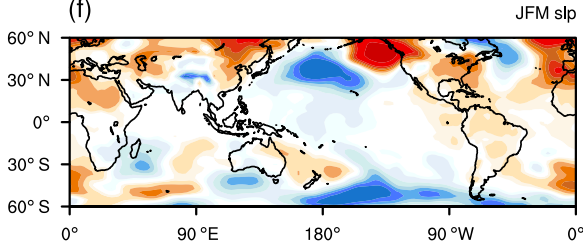

(g)

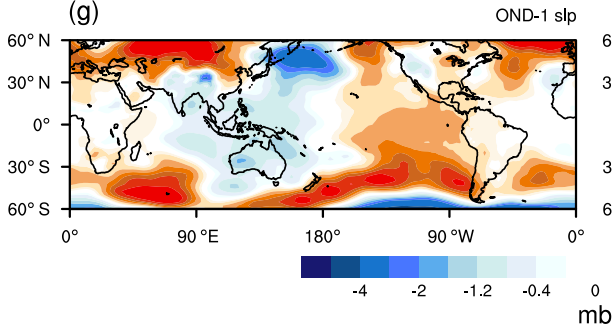

(h)

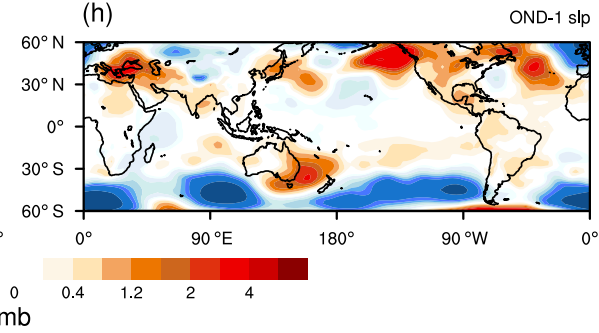

Figure 9. As in Fig. 8 but for sea level pressure (slp) anomaly composites.

mat as Fig. 8 (geopotential height plots are not shown for their high resemblance to the sea level pressure plots). From the sea level pressure composites, before the CRS, significant cyclonic anomalies over the WNP can be found from the concurrent typhoon season to even earlier periods of the same year (Fig. 9a, c, and e). After the CRS, while the WNP area is inactive with no significant cyclonic anomalies, some patterns with signs opposite of those before the CRS can be found in the mid-to-high latitude regions at varied lead times. From the zonal wind composites shown in Fig. 10, the phase reversal is marked along the Equator: whereas the zonal wind pattern evolves into (backward in time) easterly anomalies under the before-CRS scenario, strong easterly anomalies change into westerly anomalies in previous OND under the after-CRS scenario. Nevertheless, no statistically significant patterns for the wind anomalies are identified along the Equator, suggesting that further analysis should be conducted to validate the predictor-predictand relationship between the QBO and Taiwan's streamflow. Overall, the SSTA, sea level pressure, and zonal wind composites all indicate that the large-scale patterns reverse phases. Our discussion herein il- lustrates the importance of a predictor screening scheme to account for a forthcoming CRS.

\section{Summary and conclusion}

A set of teleconnection patterns is a proxy for the complex climate system, and these patterns have shown dominant effects on modulating regional hydro-climates in different seasons. A response of a region's hydro-climates to the global climate system can be characterized by the regional sink of moisture transported via various circulations and mechanisms. This study has attempted to shed light on the correlations between teleconnection patterns and Taiwan's streamflow. It is believed that streamflow data could be a more descriptive and preferable metric than precipitation relating to teleconnection patterns for its sustained (i.e. less transient) integrated water response to the climate system and direct association with water resources and hydro-meteorological hazards. Long-term JAS streamflow data derived at 28 upstream and 13 downstream gauges in Taiwan were used to correlate with 14 teleconnection indices showing signs of linkage to East Asian climate. To scrutinize the potential 
$30 \mathrm{mb}$ uwnd composite (wet-dry JAS yr) before and after CRS
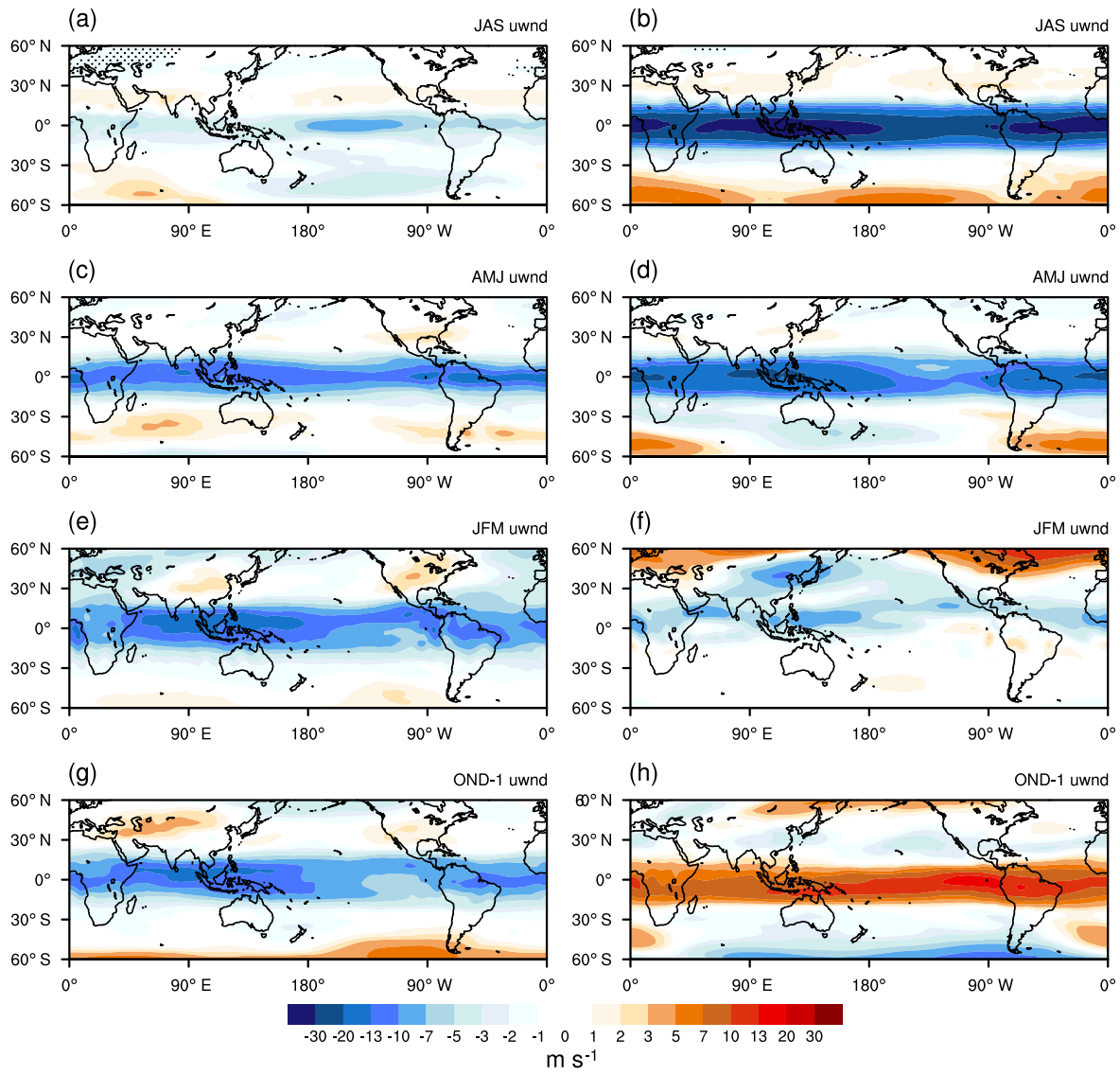

Figure 10. As in Fig. 8 but for $30 \mathrm{mb}$ zonal wind (uwnd) anomaly composites.

forecasting utility, the teleconnection indices were averaged over not only JAS, but also the preceding seasons for the calculation of concurrent and lagged correlations. In the course of our correlation analysis, it was noted that some significant correlation results based on the entire period of record were actually induced by an even more significant in-phase (or out-of-phase) relationship during a truncated time frame, indicating inherent climate regime shifts. Therefore, CRS analysis was performed to identify any significant shifts in the correlation, as well as the mean of the teleconnection indices themselves. Discussion of how the identified regime shifts impact empirical prediction was then carried out. Our key findings are summarized below.

1. Among those many teleconnection patterns, we found that the WP and PJ patterns exhibit the highest concurrent correlations with the JAS flows at both the upstream and downstream catchments in Taiwan. The determinant of such correlation performance should be the association of these patterns with cyclonic activity in the western North Pacific basin.
2. Alternatively, the lagged correlation analysis indicated that the QBO index is significantly correlated with the JAS flows in Taiwan, promoting its forecasting utility. Furthermore, some of the teleconnection indices change their relationships with the JAS flow from mostly positive concurrent correlations to negative lagged correlations.

3. We identified two shifts in the correlation between the PJ index and Taiwan's streamflow in the late 1970s and 1990s and then verified that these shifts should be bonded to some existing findings of the alteration of large-scale circulations in the Pacific around the same time.

4. Pattern correlation and composite analysis further illustrated drastic changes in large-scale patterns before and after the change point in the late 1990s. Our results overturn the convention of predictor screening widely used for empirical forecasting, as the alignment of predictors can vary in consonance with certain interannual and interdecadal oscillations. 
Our current endeavour includes applying a similar analysis framework to Taiwan's streamflow in other seasons, such as the spring rains (February to April) and Mei-Yu (May and June) seasons. Associated findings will be incorporated into a seasonal streamflow forecasting model to improve regional water resource planning and management.

Data availability. Data used in this study (e.g. seasonal streamflow and teleconnection indices) have been deposited in figshare (https://doi.org/10.6084/m9.figshare.5173018.v1). Raw daily flow records can be purchased via the link http://gweb.wra.gov.tw/ HydroApplication/index.aspx (not for commercial purposes). Raw data of teleconnection indices are available at the links shown in Table 2.

\section{The Supplement related to this article is available online at https://doi.org/10.5194/hess-21-3463-2017- supplement.}

Author contributions. C-JC and T-YL designed and conducted the analysis and co-wrote the manuscript.

Competing interests. The authors declare that they have no conflict of interest.

Acknowledgements. Work by Chia-Jeng Chen was supported by Taiwan's Ministry of Science and Technology under grant MOST 104-2625-M-005-007-MY2. Work by Tsung-Yu Lee was also supported by Taiwan's Ministry of Science and Technology under grants MOST 104-2116-M-003-005 and 105-2116-M-003-006. The authors express the upmost gratitude to Hisayuki Kubota for helping us develop the new PJ index and the Water Resources Agency and Taiwan Power Company for providing the streamflow data. The authors also acknowledge the anonymous referees for their insightful comments.

Edited by: Alberto Guadagnini

Reviewed by: two anonymous referees

\section{References}

Adler, R. F., Huffman, G. J., Chang, A., Ferraro, R., Xie, P., Janowiak, J., Rudolf, B., Schneider, U., Curtis, S., Bolvin, D., Gruber, A., Susskind, J., and Arkin, P.: The Version 2 Global Precipitation Climatology Project (GPCP) monthly precipitation analysis (1979-Present), J. Hydrometeor., 4, 1147-1167, 2003.

Alexander, M. A., Bladé, I., Newman, M., Lanzante, J. R., Lau, N. C., and Scott, J. D.: The atmospheric bridge: The influence of ENSO teleconnections on air-sea interaction over the global oceans, J. Climate, 15, 2205-2231, 2002.

Ashok, K., Behera, S. K., Rao, S. A., Weng, H., and Yamagata, T.: El Niño Modoki and its possible teleconnection, J. Geophys.
Res., 112, C11007, https://doi.org/10.1029/2006JC003798, 2007.

Baldwin, M. P., Gray, L., Dunkerton, T., Hamilton, K., Haynes, P., Randel, W., Holton, J., Alexander, M., Hirota, I., Horinouchi, T., Jones, D., Kinnersley, J., Marquardt, C., Sato, K., and Takahashi, M.: The Quasi-Biennial Oscillation, Rev. Geophys., 39, 179-229, 2001.

Barnston, A. G. and Livezey, R. E.: Classification, seasonal and persistence of low-frequency atmospheric circulation patterns, Mon. Weather Rev., 115, 1083-1126, 1987.

Behera, S. K., Luo, J. J., Masson, S., Delecluse, P., Gualdi, S., Navarra, A., and Yamagata, T.: Paramount impact of the Indian Ocean dipole on the East African short rains: A CGCM study, J. Climate, 18, 4514-4530, 2005.

Black, E., Slingo, J., and Sperber, K. R.: An observational study of the relationship between excessively strong short rains in coastal East Africa and Indian Ocean SST, Mon. Weather Rev., 131, 7494, 2003.

Chan, J. C.: Tropical cyclone activity in the western North Pacific in relation to the stratospheric quasi-biennial oscillation, Mon Weather Rev., 123, 2567-2571, 2003.

Chen, C.-J. and Georgakakos, A. P.: Hydro-climatic forecasting using sea surface temperatures: methodology and application for the southeast US, Clim. Dynam., 42, 2955-2982, 2014.

Chen, C.-J. and Georgakakos, A. P.: Seasonal prediction of East African rainfall, Int. J. Climatol., 35, 2698-2723, 2015.

Chen, J. M. and Chen, H. S.: Interdecadal variability of summer rainfall in Taiwan associated with tropical cyclones and monsoon, J. Climate, 24, 5786-5798, 2011.

Chiew, F. H. S. and McMahon, T. A.: Global ENSO-streamflow teleconnection, streamflow forecasting and interannual variability, Hydrolog. Sci. J., 47, 505-522, 2002.

Chiew, F. H. S., Piechota, T. C., Dracup, J. A., and McMahon, T. A.: El Niño/Southern Oscillation and Australian rainfall, streamflow, and drought: Links and potential for forecasting, J. Hydrol., 204, 138-149, 1998.

Choi, K. S., Wu, C. C., and Cha, E. J.: Change of tropical cyclone activity by Pacific-Japan teleconnection pattern in the western North Pacific, J. Geophys. Res., 115, D19114, https://doi.org/10.1029/2010JD013866, 2010.

Choi, K. S., Wu, C. C., and Byun, H. R.: Possible connection between summer tropical cyclone frequency and spring Arctic Oscillation over East Asia, Clim, Dynam., 38, 2613-2629, 2012.

Clark, C. O., Webster, P. J., and Cole, J. E.: Interdecadal variability of the relationship between the Indian Ocean zonal mode and East African coastal rainfall anomalies, J. Climate, 16, 548-554, 2003.

Dai, A. and Wigley, T. M. L.: Global patterns of ENSO-induced precipitation, Geophys. Res. Lett., 27, 1283-1286, 2000.

DelSole, T. and Shukla, J.: Artificial skill due to predictor screening, J. Climate, 22, 331-345, 2009.

Duan, W., Song, L., Li, Y., and Mao, J.: Modulation of PDO on the predictability of the interannual variability of early summer rainfall over south China, J. Geophys. Res., 118, 13008-13021, https://doi.org/10.1002/2013JD019862, 2013.

Enfield, D. B., Mestas-Nunez, A. M., and Trimble, P. J.: The Atlantic Multidecadal Oscillation and its relationship to rainfall and river flows in the continental U.S., Geophys. Res. Lett., 28, 2077-2080, 2001. 
Fisher, R. A.: On the "probable error" of a coefficient of correlation deduced from a small sample, Metron, 1, 3-32, 1921.

Goddard, L. S., Mason, S. J., Zebiak, S. E., Ropelewski, C. F., Basher, R., and Cane, M. A.: Current approaches to seasonal-tointerannual climate predictions, Int. J. Climatol., 21, 1111-1152, 2001

Gong, D. and Wang, S.: Definition of Antarctic oscillation index, Geophys. Res. Lett., 26, 459-462, 1999.

Guan, Z. and Yamagata, T.: The unusual summer of 1994 in East Asia: IOD teleconnections, Geophys. Res. Lett., 30, 1544, https://doi.org/10.1029/2002GL016831, 2003.

Hamlet, A. F. and Lettenmaier, D. P.: Columbia River streamflow forecasting based on ENSO and PDO climate signals, J. Water Res. Pl., 125, 333-341, 1999.

Hare, S. R. and Mantua, N. J.: Empirical evidence for North Pacific regime shifts in 1977 and 1989, Prog. Oceanogr., 47, 103-145, 2000.

Harrison, D. E. and Larkin, N. K.: El Niño-southern oscillation sea surface temperature and wind anomalies, Rev. Geophys., 36, 353-399, 1998.

Hidalgo-Muñoz, J. M., Gámiz-Fortis, S. R., Castro-Díez, Y., Argüeso, D., and Esteban-Parra, M. J.: Long-range seasonal streamflow forecasting over the Iberian Peninsula using largescale atmospheric and oceanic information, Water Resour. Res., 51, 3543-3567, 2015.

Ho, C. H., Kim, H. S., Jeong, J. H., and Son, S. W.: Influence of stratospheric quasi-biennial oscillation on tropical cyclone tracks in the western North Pacific, Geophys. Res. Lett., 36, L06702, https://doi.org/10.1029/2009GL037163, 2009.

Hong, C. C., Wu, Y. K., Li, T., and Chang, C. C.: The climate regime shift over the Pacific during 1996/1997, Clim. Dynam., 43, 435446, 2014a.

Hong, L.-C., Ho, L., and Jin, F.-F.: A Southern Hemisphere booster of super El Niño, Geophys. Res. Lett., 41, 2142-2149, 2014b.

Huang, B., Banzon, V. F., Freeman, E., Lawrimore, J., Liu, W., Peterson, T. C., Smith, T. M., Thorne, P. W., Woodruff, S. D., and Zhang, H. M.: Extended reconstructed sea surface temperature version 4 (ERSST. v4). Part I: upgrades and intercomparisons, J. Climate, 28, 911-930, 2015.

Huang, J. C., Yu, C. K., Lee, J. Y., Cheng, L. W., Lee, T. Y., and Kao, S. J.: Linking typhoon tracks and spatial rainfall patterns for improving flood lead time predictions over a mesoscale mountainous watershed, Water Resour. Res., 48, W09540, https://doi.org/10.1029/2011WR011508, 2012.

Hurrell, J. W.: Decadal trends in the North Atlantic Oscillation: regional temperatures and precipitation, Science, 269, 676-679, 1995.

Kahya, E. and Dracup, J. A.: US streamflow patterns in relation to the El Niño/Southern Oscillation, Water Resour. Res., 29, 24912503, 1993.

Kalnay, E., Kanamitsu, M., Kistler, R., Collins, W., Deaven, D., Gandin, L., Iredell, M., Saha, S., White, G., Woollen, J., and Zhu, Y.: The NCEP/NCAR 40-Year Reanalysis Project, B. Am. Meteorol. Soc., 77, 437-471, 1996.

Kiladis, G. N. and Diaz, H. F.: Global climatic anomalies associated with extremes in the Southern Oscillation, J. Climate, 2, 10691090, 1989

Kim, H. M. and Webster, P. J.: Extended-range seasonal hurricane forecasts for the North Atlantic with a hybrid dynamical-statistical model, Geophys. Res. Lett., 37, L21705, https://doi.org/10.1029/2010GL044792, 2010.

Kosaka, Y. and Nakamura, H.: Structure and dynamics of the summertime Pacific-Japan teleconnection pattern, Q. J. Roy. Meteor. Soc., 132, 2009-2030, 2006.

Kosaka, Y., Xie, S. P., Lau, N. C., and Vecchi, G. A.: Origin of seasonal predictability for summer climate over the Northwestern Pacific, P. Natl. Acad. Sci. USA, 110, 7574-7579, 2013.

Kruskal, W. H. and Wallis, W. A.: Use of ranks in one-criterion variance analysis, J. Amer. Statist. Assoc., 47, 583-621, 1952.

Kubota, H., Kosaka, Y., and Xie, S. P.: A 117-year long index of the Pacific Japan pattern with application to interdecadal variability, Int. J. Climatol., 36, 1575-1589, 2016.

Li, H., Dai, A., Zhou, T., and Lu, J.: Responses of East Asian summer monsoon to historical SST and atmospheric forcing during 1950-2000, Clim. Dynam., 34, 501-514, 2010.

Liang, A., Oey, L., Huang, S., and Chou, S.: Long-term trends of typhoon-induced rainfall over Taiwan: In situ evidence of poleward shift of typhoons in western North Pacific in recent decades, J. Geophys. Res., 122, 2750-2765, 2017.

Livezey, R. E. and Chen, W. Y.: Statistical field significance and its determination by Monte Carlo techniques, Mon. Weather Rev., 111, 46-59, 1983.

Mantua, N. J., Hare, S. R., Zhang, Y., Wallace, J. M., and Francis, R. C.: A Pacific interdecadal climate oscillation with impacts on salmon production, B. Am. Meteorol. Soc., 78, 1069-1079, 1997.

McCabe, G. J. and Dettinger, M. D.: Decadal variations in the strength of ENSO teleconnections with precipitation in the western United States, Int. J. Climatol., 19, 1399-1410, 1999.

McPhaden, M. J., Lee, T., and McClurg, D.: El Niño and its relationship to changing background conditions in the tropical Pacific, Geophys. Res. Lett., 38, L15709, https://doi.org/10.1029/2011GL048275, 2011.

Mei, W. and Xie, S. P.: Intensification of landfalling typhoons over the northwest Pacific since the late 1970s, Nat. Geosci., 9, 753757, 2016.

Miller, A. J., Cayan, D. R., Barnett, T. P., Graham, N. E., and Oberhuber, J. M.: The 1976-77 climate shift of the Pacific Ocean, Oceanography, 7, 21-26, 1994.

Moradkhani, H. and Meier, M.: Long-lead water supply forecast using large-scale climate predictors and independent component analysis, J. Hydrol. Eng., 15, 744-762, 2010.

Naujokat, B.: An update of the observed quasi-biennial oscillation of the stratospheric winds over the tropics, J. Atmos. Sci., 43, 1873-1877, 1986.

Nita, T.: Convective activities in the tropical western Pacific and their impact on the northern hemisphere summer circulation, J. Meteor. Soc. Jpn., 65, 373-390, 1987.

Palmer, T. N. and Anderson, D. L. T.: The prospects for seasonal forecasting - a review paper, Q. J. Roy. Meteorol. Soc., 120, 755793, 1994.

Pettitt, A. N.: A non-parametric approach to the change-point problem, Appl. Stat., 28, 126-135, 1979.

Rajeevan, M., Pai, D. S., Kumar, R. A., and Lai, B.: New statistical models for long-range forecasting of southwest monsoon rainfall over India, Clim. Dynam., 28, 813-828, https://doi.org/10.1007/s00382-006-0197-6, 2007. 
Robertson, D. E. and Wang, Q. J.: A Bayesian approach to predictor selection for seasonal streamflow forecasting, J. Hydrometeor., 13, 115-171, 2012.

Rodionov, S.: A sequential algorithm for testing climate regime shifts, Geophys. Res. Lett., 31, L09204, https://doi.org/10.1029/2004GL019448, 2004.

Rodionov, S.: A sequential method for detecting regime shifts in the mean and variance, in: Large-Scale Disturbances (Regime Shifts) and Recovery in Aquatic Ecosystems: Challenges for Management Toward Sustainability, Proceedings of 2005 UNESCOROSTE/BAS Workshop on Regime Shifts, Varna, Bulgaria, 1416 June 2005, 69-72, 2005.

Rodionov, S.: Sequential method of detecting abrupt changes in the correlation coefficient and its application to Bering Sea climate, Climate, 3, 474-491, 2015.

Ropelewski, C. F. and Halpert, M. S.: North American precipitation and temperature patterns associated with the El Niño/Southern Oscillation (ENSO), Mon. Weather Rev., 114, 2352-2362, 1986.

Ropelewski, C. F. and Halpert, M. S.: Global and regional scale precipitation patterns associated with the El Niño/Southern Oscillation, Mon. Weather Rev., 115, 1606-1626, 1987.

Ropelewski, C. F. and Halpert, M. S.: Precipitation patterns associated with the high index phase of the southern oscillation, J. Climate, 2, 268-284, 1989.

Ropelewski, C. F. and Halpert, M. S.: Quantifying Southern Oscillation-Precipitation relationships, J. Climate, 9, 10431059, 1996.

Saji, N. H., Goswami, B. N., Vinayachandran, P. N., and Yamagata, T.: A dipole mode in the tropical Indian Ocean, Nature, 401, 360363, 1999.

Schlesinger, M. E. and Ramankutty, N.: An oscillation in the global climate system of period 65-70 years, Nature, 367, 723-726, 1994
Thompson, D. W. J. and Wallace, J. M.: The Arctic Oscillation signature in the wintertime geopotential height and temperature fields, Geophys. Res. Lett., 25, 1297-1300, 1998.

Trenberth, K. E.: The Definition of El Niño, B. Am. Meteorol. Soc., 78, 2771-2777, 1997.

Trenberth, K. E. and Stepaniak, D. P.: Indices of El Niño evolution, J. Climate, 14, 1697-1701, 2001.

van den Dool, H.: Empirical Methods in Short-Term Climate Prediction, Oxford University Press, 2007.

Wallace, J. M. and Gutzler, D. S.: Teleconnections in the geopotential height field during the Northern Hemisphere winter, Mon. Weather Rev., 109, 784-812, 1981.

Wang, B., Wu, R., and Fu, X.: Pacific-East Asian teleconnection: How does ENSO affect East Asian climate?, J. Climate, 13, 1517-1536, 2000.

Wang, H. and Fan, K.: Central-north China precipitation as reconstructed from the Qing dynasty: Signal of the Antarctic Atmospheric Oscillation, Geophys. Res. Lett., 32, L24705, https://doi.org/10.1029/2005GL024562, 2005.

Wilks, D. S.: Statistical Methods in the Atmospheric Sciences, Academic press, 2011.

Xiang, B., Wang, B., and Li, T.: Seasonally Evolving Dominant Interannual Variability Modes of East Asian Climate, J. Climate, 22, 2992-3005, 2009.

Yang, S., Lau, K. M., and Kim, K. M.: Variations of the East Asian jet stream and Asian-Pacific-American winter climate anomalies, J. Climate, 15, 306-325, 2002.

Yihui, D. and Chan, J. C.: The East Asian summer monsoon: an overview, Meteor. Atmos. Phys., 89, 117-142, 2005. 